\title{
NASA sets launch schedules for future missions
}

\section{Washington}

NASA, the US National Aeronautics and Space Administration's last week released the latest launch schedule for both the shuttle - now scheduled to resume operations either later this month or early next - and its fleet of expendable launch vehicles (ELVs).

Because of inflexible launch windows, the three forthcoming Solar System missions retain their prized manifest slots, but the Hubble Space Telescope's launch date has been pushed back by seven months. Priority in shuttle assignments went to missions with fixed launch windows and those which require the specific capabilities of the shuttle. Magellan, the
The delay will also mean that more telescope systems can be made ready before launch. Giacconi says hardware and software improvements have been proceeding smoothly. New solar cells provided by the European Space Agency will improve power levels by about 15 per cent, and switching from nickel-cadmium to nickel-hydrogen batteries will improve energy storage and cycling capabilities.

There has also been a compromise on the mission profile for the telescope. At first, when the launch was expected during a period of high solar activity, mission managers sought to place the telescope into the highest orbit possible so it could tolerate a more rapid decay. But NASA

\begin{tabular}{llll}
\hline & \multicolumn{1}{c}{ NASA's launch schedule } \\
\hline Sep & 88 & ELV (Atlas) & NOAA-H \\
Sep & 88 & Shuttle (Discovery) & TDRS-C \\
Nov & 88 & Shuttle (Atlantis) & DoD \\
Feb & 89 & Shuttle (Discovery) & TDRS-D \\
Apr & 89 & Shuttle (Atlantis) & Magellan \\
May & 89 & ELV (Delta) & Cosmic Background Explorer \\
May & 89 & ELV (Atlas) & NOAA-D \\
Jul & 89 & Shuttle (Columbia) & DoD \\
Aug & 89 & Shuttle (Discovery) & DoD \\
Sep & 89 & ELV (Atlas Centaur) & FLTSATCOM-F8 \\
Oct & 89 & Shuttle (Atlantis) & Galileo \\
Nov & 89 & Shuttle (Columbia) & LDEF-1R, SYNCOM IV-5 \\
Dec & 89 & Shuttle (Discovery) & DoD \\
Feb & 90 & Shuttle (Atlantis) & Hubble Space Telescope \\
Feb & 90 & ELV (Delta) & ROSAT \\
Feb & 90 & ELV (Scout) & Transit-27 \\
Mar & 90 & Shuttle (Columbia) & Astro-1, BBXRT \\
Apr & 90 & Shuttle (Discovery) & Gamma Ray Observatory \\
\hline
\end{tabular}

Venus radar mapper, will be the first pure science mission to launch. The NOAA-H satellite - primarily an operational satellite for weather forecasting - has a solar back-scatter ultraviolet measuring instrument that can give vertical profiles of atmospheric ozone, but does not provide total atmospheric ozone measurements.

The Galileo mission to Jupiter and the Ulysses mission that swings out of the ecliptic at Jupiter to study the Sun's poles have essentially the same launch windows, but a decision was made last year to give Galileo the 1989 launch and Ulysses a 1990 launch.

It is the space telescope that has absorbed the biggest delay, but although the delay is a blow to morale, Riccardo Giacconi, director of the Space Telescope Science Institute, says he is more convinced than ever that NASA is committed to the mission, and will do everything possible to permit it to be launched under the current schedule. Giacconi says an example of the commitment is NASA's willingness to keep the telescope 'ready to launch' from August next year. This means that if any intervening payload is cancelled, the telescope can fly instead. was unhappy with this, because if the expected decay did not occur, the shuttle would be at the edge of its performance capabilities when it attempts a planned repair mission. The repair mission could place more demands on the shuttle than deployment, as precise matching of orbits will require a large propellant margin. With deployment, slight deviations in projected orbits can easily be tolerated

Under the compromise, the shuttle's main engine will boost the telescope into an elliptical orbit 310 by 330 nautical miles. The orbit can then be converted into a circular one at any altitude in that range depending on existing solar activity.

The delay did mean scheduling headaches for NASA managers who will have to transport the telescope from Sunnyvale, California, where it is stored in one of the world's largest clean rooms, to Cape Canaveral in Florida. The spacecraft was to be moved in November on a reinforced-hulled ship normally used for supplying arctic fleets, but that has been cancelled. Now NASA is looking into the possibility a flight aboard a $\mathrm{C}-5 \mathrm{~A}$ jet transport, or possibly a later ocean ride.

Joseph Palca

\section{Genentech patent}

GENENTECH last week added yet another significant biotechnology patent to its portfolio. The California company announced that it had been granted a US patent covering the human recombinant version of the blood clot-dissolving drug tissue plasminogen activator (TPA) and the means for producing it.

The patent's 11 claims outline Genentech's ownership of the DNA sequences coding for human TPA, its exact amino acid sequence, and all recombinant vectors, microorganisms and cell lines which are used to produce it. TPA was first cloned and expressed in 1982 by Genentech employees together with Desire Collen from the University of Leuven in Belgium (see Nature 301, 214; 1983). A US patent covering purified TPA was licensed by Genentech in June (see Nature 333, 790; 1988).

The latest patent covers the same technology as Genentech's UK patent on TPA, which is currently the subject of a court battle with Wellcome plc (see Nature 328 $189 ; 1987$ ). Based on the new patent, Genentech has filed US suits against Wellcome plc's US subsidiary, Burroughs Wellcome, and its collaborator, Genetics Institute.

\section{New federal awards} C.E.

THREE US federal agencies last week jointly announced new awards totalling $\$ 9.5$ million for plant science centres. The largest award $-\$ 5.7$ million over five years from the National Science Foundation (NSF) - goes to Cornell University for a centre for the experimental analysis and transfer of plant genes.

The three awards are part of a joint Plant Science Centers Program established by NSF, the Department of Agriculture (USDA) and the Department of Energy (DoE). USDA has awarded $\$ 1.3$ million to Michigan State University for a centre for genetic and biochemical alteration of plant lipids and starch, and DoE will give Arizona State University $\$ 2.5$ million for a centre for the study of early events of photosynthesis. NSF will add $\$ 610,000$ for equipment costs at the Arizona centre. J.P.

\section{Collaboration begins}

Four projects linking research institutes in East and West Germany were given the goahead on 22 August in East Berlin. The projects, which include nuclear reactor safety research and high energy physics, are among 27 joint projects agreed upon in principle by the two states during the visit of East German leader Erich Honecker to Bonn in September, 1987. Significantly, the new projects include researchers from West Berlin, whose participation had been the sticking point for many years in negotiations over scientific cooperation between West Germany and the Soviet bloc. 